\title{
Hydrodynamic Studies on Conventional and Tapered Fluidized Bed
}

\author{
Deo Karan Ram ${ }^{1}$, Alok Tiwari ${ }^{2}$ \\ ${ }^{1}$ Department of Chemical Engineering, National Institute of Technology, Rourkela, Dist-Sundargarh, Odisha, India \\ ${ }^{2}$ Guru Ghasidas University, Department of Chemical Engineering, Bilaspur (C.G.), India
}

\begin{abstract}
In this project the determination of maximum pressure drop, minimum fluidization velocity, minimum bubbling velocity and fluidization index for various powders are to be studied using a conventional cylindrical bed and a tapered bed. Tapered beds have a velocity gradient along the axis unlike conventional beds. They have been used as an alternative to conventional cylindrical beds to deal with problems such as slugging. Initially air at ambient conditions $(310 \mathrm{~K})$ is to be used as the fluidizing medium. High temperature studies will also be carried out using a High temperature fluidized bed (Air temperature up to $1173 \mathrm{~K}$ ).
\end{abstract}

Keywords: Tapered, conventional, fluidized bed, ambient and high temperature

\section{Introduction}

Most of the gas-solid fluidization behaviour studies that have been reported are for straight cylindrical or columnar fluidized beds; although a considerable portion of the fluidized beds have inclined walls or have a tapered bottom section. A velocity gradient exists in the axial direction in tapered bed leading to unique dynamic characteristics of the bed. Due to this characteristic, tapered fluidized beds have found wide application in many industrial processes such as, waste water treatment, immobilized biofilm reaction, incineration of waste materials, coating of nuclear fuel particles, crystallization, coal gasification, roasting sulfide ores and food processing, etc. Tapered fluidized beds can be operated smoothly without any instability, i.e. with less pressure fluctuations. Tapered fluidized beds are very useful for fluidization of materials with a wide particle size distribution, as well as for exothermic reactions and also for extensive particle mixing. Despite their widespread application, much of the development and design of tapered fluidized bed reactors have been empirical in nature as the complex behaviour of gas-solid flow in these systems makes flow modelling a challenging task. In addition, numerical solutions of complex non-linear equations, with moving phase boundaries, are difficult to obtain. However, with increasing computational capabilities and computational fluid dynamics (CFD) tools in recent years, several researchers are involved in studying the hydrodynamics of gas-solid systems, which would be useful in the design, optimization and scale-up process.

Due to good solid mixing, high heat transfer, large contact surface area, etc., fluidized bed technology has been exhaustively used in many industrial processes such as coal combustion, gasification, polymerization and catalytic cracking. There are many variables determining the smooth running of fluidized beds like bubble frequency, bed expansion and minimum fluidization velocity $U$ that plays a critical role in the design and operation of fluidized beds is one of the most important parameters. Therefore, numerous investigations have been undertaken to study the variation of $\mathrm{U}$ then, $\mathrm{U}$ under different operational conditions. To predict $\mathrm{U}$ precisely, many previous studies have proposed the empirical correlations, as listed in Table 1.

Among them, most correlations have been developed for narrow-cut particles. However, when dealing with natural minerals or coal combustion etc., wide PSD particles are usually fluidized as bed materials. At this point, the prediction errors for the traditional correlations are too large to give useful results. In order to remedy this situation, some correlations have been developed for the particles with wide PSD, such as C8 in Table 1 proposed by Zhejiang University (in what follows, it's referred to as "ZJC"), C9 proposed by Northwest University (China) (referred to as "NWC") and C10 proposed by Huazhong University of Science and Technology (referred to as "HZC"). However, these correlations also have their short comings.

\section{Literature Survey}

Application of tapered fluidized bed technique is versatile in the field of high temperature processes viz. coal combustion and gasification, gas-solid catalytic reaction, etc. Prediction of minimum fluidized velocity at elevated temperatures is a pre-requisite in the design and operation of high temperature fluidized beds. Several investigations have been made during the last few decades and the Ergun's [13] equation has been used to correlate the experimental data in most of the cases [14-20]. Equations with particle sphericity range have been proposed by Lukas et al. [21] based on Brownell's approach [22] of bed compactness to eliminate the minimum bed porosity dependence of the minimum fluidization velocity. Yamazaki et al. [23] have developed a model for predicting minimum fluidization velocity at elevated temperatures based on quantitative relationship between the velocity and the adhesive force of particles. In most of the above elevated temperature studies, spherical particles were frequently used in order to eliminate eventual complications caused by nonspherical shapes of solids which is encountered in actual practice. Further all the studies were conducted in conventional (cylindrical) beds. In the recent past, fluidization in tapered bed is gaining importance in view of its potential application in gas-solid system involving continuously decreasing particle size in combustion and gasification of coal, reduction of iron ores [24], etc. Although some 


\section{International Journal of Science and Research (IJSR) \\ ISSN (Online): 2319-7064}

Index Copernicus Value (2013): 6.14 $\mid$ Impact Factor (2014): 5.611

investigations have been carried out in conical bed $[25,26]$ and tapered bed $[27,28]$ for prediction of minimum fluidization velocity under ambient conditions, similar data at elevated temperature conditions in tapered bed are not available. In this present work, investigations have been carried out at elevated temperatures to obtain the correlation of minimum fluidization velocity (independent of bed voidage) in tapered bed for gas-solid system and the correlation has been compared with values obtained by equation of Sau et al. [28] proposed for tapered bed in ambient conditions in gas-solid systems. In addition, the best fit to the presented results have also been compared with the equations developed for conventional (cylindrical) beds available in the literature under ambient conditions and at elevated temperatures.

Although many fluidized beds are operated at high temperature, before 1980 's, most experiments determining U have been conducted at ambient temperature. Along with the wide applications of fluidized beds to the industry, the prediction errors of Umf at high temperature began to attract more attention. Botterill et al. (1982) [29] have observed that the $\mathrm{U}$ of Geldart B-type particles decreases with the increasing bed temperature, opposite to the behaviour of Geldart D-type particles. Pattipati and Wen [30] have pointed out that the increasing temperature causes a slight decrease of Umf for particles, whose diameter is smaller than $2 \mathrm{~mm}$, unlike particles larger than $2 \mathrm{~mm}$. Goo et al. [31] have noted that Umf decreases as the bed temperature increases, regardless of particle diameters or particle types. $\mathrm{Wu}$ and Baeyens [32] and Subramani et al. [33] have also observed similar behaviour. Formisani et al. [34] have showed that the increase in bed temperature has no effect on the $\mathrm{U} \mathrm{mf}$ of fine particles but leads to a decrease in Umf for coarse particles. Chiou et al. pointed out that bed temperature and PSD can in fluence the Umf simultaneously, making Umf vary nonmonotonically with temperature [35].

\section{Method and Experimental Details}

\subsection{Tapered fluidized bed at ambient temperature}

The tapered bed used in this study has column bottom and top diameters of $41.5 \mathrm{~mm}$ and $540 \mathrm{~mm}$ respectively. The tapered angle was $7.47^{\circ}$. A cloth having a pore size less than $20 \mu \mathrm{m}$ was used as the distributor. A U Tube Manometer having Carbon tetrachloride as the Manometric fluid (density $=1630$ $\mathrm{Kg} / \mathrm{m} 3$ ) was used to measure the bed pressure drop. Air was used as the fluidizing medium (At Temperature $=310 \mathrm{~K}$, Density $=1.17 \mathrm{~kg} / \mathrm{m} 3$ ). A silica gel tower was used to remove the moisture present in the air. A rotameter having a range of 0-50 LPM was used to measure the air flow rates. Hematite powder of particle size $20 \mu \mathrm{m}$ was used. The ratio of mass/poured volume of the powder gives us the bulk density. Before the start of the tests the bed was fluidized once so that the powder bed is level so that the initial height can be noted properly.

The voidage was measured by the formula-

Voidage $=1$ - (bulk density/ Particle density)

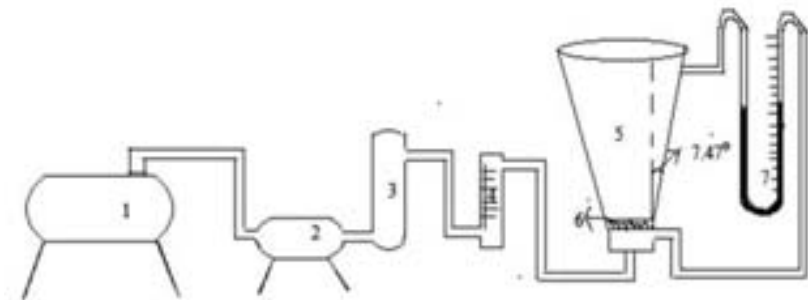

Figure 1: Experimental Setup: (1) Compressor, (2) Receiver, (3) Silica gel tower, (4) Air Rotameter, (5) Tapered bed with tapered angle 7.47o, (6) Powder bed, (7) U-tube manometer.

\subsection{Conventional fluidized bed at ambient temperature-}

The experiment was carried put using hematite as solid particle, compressed air as gas. Initially the column is filled with hematite and for different gas flow rate variation of pressure drop and bed height is taken. The scope of the experiment has been presented in the Table below.

Pressure drop and the expanded bed height were noted. Experiments were conducted at normal temperature of $(30 \pm 5)$ $0 \mathrm{C}$. The temperature of the air was presumed to be at normal condition i.e.at $250 \mathrm{C}$. The procedure was repeated for different gas flow rate, particles of 10 micrometer sizes and varying initial static bed heights.

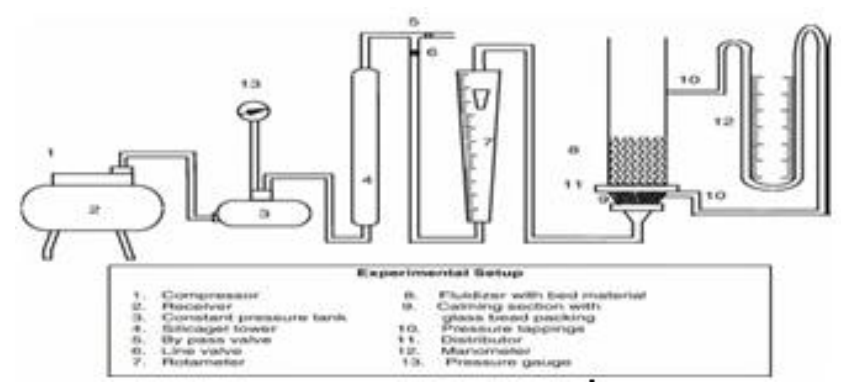

Figure 2: Experimental set-up of conventional fluidized bed 


\section{International Journal of Science and Research (IJSR) \\ ISSN (Online): 2319-7064}

Index Copernicus Value (2013): 6.14 | Impact Factor (2014): 5.611

\section{Observations and Calculations}

\subsection{Conventional fluidized bed at ambient temperature}

Table 1: At Bed height $=6 \mathrm{~cm}$ for hematite

\begin{tabular}{|c|c|c|c|c|c|c|c|}
\hline Flow rate (LPM) & $\begin{array}{c}\text { Velocity } \\
(\mathrm{M} / \mathrm{S}) * 10^{-3}\end{array}$ & $\begin{array}{c}\text { Manometer } \\
(\text { Maximum }) \\
\mathrm{H}_{1}\end{array}$ & $\begin{array}{c}\text { Manometer } \\
(\text { Minimum }) \\
\mathrm{H}_{2}\end{array}$ & $\begin{array}{c}\Delta \mathrm{H}=\left(\mathrm{H}_{1}-\mathrm{H}_{2}\right) \\
(\mathrm{cm})\end{array}$ & $\begin{array}{c}\Delta \mathrm{P}=\rho g \Delta \mathrm{H} \\
(\mathrm{Kpa})\end{array}$ & $\begin{array}{c}\text { Bed height } \\
\mathrm{Lf}(\mathrm{Cm})\end{array}$ & $\begin{array}{c}(\mathrm{Lf}- \\
\mathrm{Lm}) / \mathrm{Lm}\end{array}$ \\
\hline 1.5 & 6.48 & 25 & 24.8 & 0.9 & 1.19 & 12 & 1 \\
\hline 4.5 & 19.86 & 25.2 & 24.1 & 1.1 & 1.58 & 14 & 1.3 \\
\hline 6.5 & 28.04 & 25.3 & 24.0 & 1.3 & 1.73 & 17 & 1.83 \\
\hline 7 & 30.46 & 25.4 & 23.9 & 1.4 & 1.86 & 18 & 2 \\
\hline 8 & 34.76 & 25.3 & 24.0 & 1.4 & 1.86 & 20 & 2.33 \\
\hline 9 & 38.88 & 25.4 & 24.0 & 1.4 & 1.86 & 21 & 2.5 \\
\hline
\end{tabular}

Table 2: At Bed height $=7 \mathrm{~cm}$ for hematite

\begin{tabular}{|c|c|c|c|c|c|c|c|}
\hline Flow rate (LPM) & $\begin{array}{c}\text { Velocity } \\
(\mathrm{M} / \mathrm{S}) * 10^{-3}\end{array}$ & $\begin{array}{c}\text { Manometer } \\
(\text { Maximum) } \\
\mathrm{H}_{1}\end{array}$ & $\begin{array}{c}\text { Manometer } \\
(\text { Minimum }) \\
\mathrm{H}_{2}\end{array}$ & $\begin{array}{c}\Delta \mathrm{H}=\left(\mathrm{H}_{1}-\mathrm{H}_{2}\right) \\
(\mathrm{cm})\end{array}$ & $\begin{array}{c}\Delta \mathrm{P}=\rho g \Delta \mathrm{H} \\
(\mathrm{Kpa})\end{array}$ & $\begin{array}{c}\text { Bed height } \\
\mathrm{Lf}(\mathrm{Cm})\end{array}$ & $\begin{array}{c}(\mathrm{Lf}- \\
\mathrm{Lm}) / \mathrm{Lm}\end{array}$ \\
\hline 1.0 & 4.28 & 25.1 & 24.0 & 1.2 & 1.86 & 8.5 & 0.46 \\
\hline 2.0 & 8.64 & 25.3 & 23.9 & 1.4 & 1.98 & 12.0 & 0.54 \\
\hline 4.5 & 19.36 & 25.5 & 23.8 & 1.7 & 2.26 & 15.5 & 1.18 \\
\hline 6.5 & 28.12 & 25.6 & 23.6 & 1.7 & 2.26 & 19.0 & 2.47 \\
\hline 8.6 & 36.79 & 25.7 & 23.5 & 1.8 & 2.39 & 20.0 & 2.63 \\
\hline
\end{tabular}

Table 3: At static Bed height $=9 \mathrm{~cm}$ for hematite

\begin{tabular}{|c|c|c|c|c|c|c|c|}
\hline $\begin{array}{c}\text { Flow Rate } \\
(\mathrm{LPM})\end{array}$ & $\begin{array}{c}\text { Velocity } \\
(\mathrm{M} / \mathrm{S}) * 10^{-3}\end{array}$ & $\begin{array}{c}\text { Mano meter } \\
(\text { Maximum }) \mathrm{H}_{1}\end{array}$ & $\begin{array}{c}\text { Mano meter } \\
(\text { Mini mum }) \mathrm{H}_{2}\end{array}$ & $\begin{array}{c}\Delta \mathrm{H}=\left(\mathrm{H}_{1}-\mathrm{H}_{2}\right) \\
(\mathrm{cm})\end{array}$ & $\begin{array}{c}\Delta \mathrm{P}=\rho \mathrm{g} \Delta \mathrm{H} \\
(\mathrm{Kpa})\end{array}$ & $\begin{array}{c}\text { Bed height } \\
\mathrm{Lf}(\mathrm{Cm})\end{array}$ & $\begin{array}{c}(\mathrm{Lf}-\mathrm{Lm}) \\
/ \mathrm{Lm}\end{array}$ \\
\hline 4.5 & 14.44 & 25.7 & 24.5 & 1.2 & 1.5 & 24 & 1.66 \\
\hline 7.5 & 32.4 & 25.8 & 23.9 & 1.9 & 2.5 & 30 & 2.33 \\
\hline 9.5 & 40.36 & 25.0 & 23.2 & 1.8 & 2.39 & 36 & 3 \\
\hline 13.5 & 56.58 & 25.1 & 23.1 & 2.0 & 2.66 & 38 & 3.33 \\
\hline 16.5 & 71.28 & 25.1 & 23.0 & 2.1 & 2.79 & 37 & 3.01 \\
\hline
\end{tabular}

Table 4: At Static Bed height $=10 \mathrm{~cm}$ for hematite

\begin{tabular}{|c|c|c|c|c|c|c|c|}
\hline Flow rate (LPM) & $\begin{array}{c}\text { Velocity } \\
(\mathrm{M} / \mathrm{S}) * 10^{-3}\end{array}$ & $\begin{array}{c}\text { Mano meter } \\
(\text { Maximum }) \\
\mathrm{H}_{1}\end{array}$ & $\begin{array}{c}\text { Mano meter } \\
(\text { Minimum }) \\
\mathrm{H}_{2}\end{array}$ & $\begin{array}{c}\Delta \mathrm{H}=\left(\mathrm{H}_{1}-\mathrm{H}_{2}\right) \\
(\mathrm{cm})\end{array}$ & $\begin{array}{c}\Delta \mathrm{P}=\rho \mathrm{g} \Delta \mathrm{H} \\
(\mathrm{Kpa})\end{array}$ & $\begin{array}{c}\text { Bed height } \\
\mathrm{Lf}(\mathrm{Cm})\end{array}$ & $\begin{array}{c}(\mathrm{Lf}-\mathrm{Lm}) \\
/ \mathrm{Lm}\end{array}$ \\
\hline 5 & 21.6 & 25.3 & 24.2 & 1.1 & 1.46 & 27 & 1.7 \\
\hline 7 & 30.24 & 25.8 & 23.8 & 2.0 & 2.66 & 35 & 2.5 \\
\hline 9 & 38.82 & 25.9 & 23.7 & 2.2 & 2.93 & 45 & 3.5 \\
\hline 11 & 47.58 & 26.0 & 23.6 & 2.4 & 3.19 & 47 & 3.7 \\
\hline 15 & 64.8 & 26.0 & 23.6 & 2.4 & 3.19 & 48 & 3.8 \\
\hline
\end{tabular}

Figure 3: The graph between the superficial velocity and the pressure drop for conventional bed 


\section{International Journal of Science and Research (IJSR) \\ ISSN (Online): 2319-7064}

Index Copernicus Value (2013): 6.14 | Impact Factor (2014): 5.611

\subsection{Tapered fluidized bed at ambient temperature}

Table 5: Experimental data in Tapered fluidized bed at ambient temperature

\begin{tabular}{|c|c|c|c|c|c|}
\hline Material & $\begin{array}{c}\text { Particle Diameter } \\
(\mu \mathrm{m})\end{array}$ & Bed Height $(\mathrm{cm})$ & $\begin{array}{c}\text { Experimental Pressure } \\
\text { Drop }(\mathrm{Pa})\end{array}$ & $\begin{array}{c}\text { Experimental } U_{m f} \\
(\mathrm{~m} / \mathrm{sec})\end{array}$ & $\begin{array}{c}\text { Experimental } U_{m b} \\
(\mathrm{~m} / \mathrm{sec})\end{array}$ \\
\hline \multirow{3}{*}{$\begin{array}{l}\text { Hem } \\
\text { atite }\end{array}$} & \multirow{3}{*}{20} & 5.5 & 518.8 & 0.074 & 0.074 \\
\hline & & 10 & 598.6 & 0.129 & 0.129 \\
\hline & & 15 & 705.0 & 0.154 & 0.154 \\
\hline
\end{tabular}

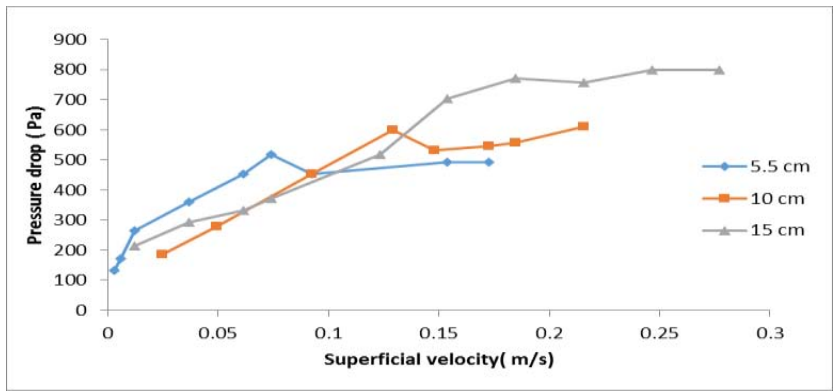

Figure 4: Plot of Pressure drop vs superficial velocity for bed height of 5.5,10 \& $15 \mathrm{~cm}$ using hematite

\section{Results and Discussion}

\subsection{Conventional bed at ambient}

Pressure Drop

The bed pressure drop decreases with the increase in gas velocity and with the increase in bed mass the pressure drop increases.

\section{Minimum liquid fluidization velocity}

The minimum liquid fluidization velocity decreases with the increase in gas velocity, and increases with the increase in particle size. Minimum liquid fluidization velocity is independent of initial static bed heights.

\subsection{Tapered bed at ambient temperature}

Bed Height and Minimum fluidization velocity (Umf)

As can be seen in Table 7 the minimum fluidization velocity of the sample of hematite increased with increase in bed height.

\section{Minimum bubbling velocity (Umb)}

The minimum fluidization velocity and bubbling velocity for the hematite powder sample was equal at the various bed heights that they were studied.

\section{Fluidization index}

A fluidization index value of 1 was observed indicates that the beds formed by the various powder samples have very less capacity to hold gases i.e. are less aeratable (Abrahamsen and Geldart, 1980)

\section{Conclusions}

The experiments were carried out at using a conventional cylindrical bed and a bed having a constant tapered angle by varying the bed heights for a variety of gas-solid systems. The effect of initial bed height of powder samples on minimum fluidization velocity and bubbling velocity were studied. Previous researches on fluidization in tapered beds have stated that minimum fluidization velocity is independent of the tapered bed height. Our results using hematite in tapered beds didn't support this assertion

\section{References}

[1] C.Y. Wen, Y.H. Yu, Mechanics of fluidization, Chemical Engineering Progress Symposium Series 62 (1966) 100111.

[2] P. Gourgeoi, P. Grenier, The ratio of terminal velocity to minimum fluidization velocity for spherical particles, The Canadian Journal of Chemical Engineering 46(1968) 325-328.

[3] S.C. Saxena, G.J. Vogel, The measurement of incipient fluidization velocities in a bed of coarse dolomite at temperature and pressure, Transactions of the Institution of Chemical Engineers 55 (1977) 187-189.

[4] M. Nakamura, Y. Hamada, S. Toyama, An experimental investigation of minimum fluidization velocity at elevated temperatures and pressures, The Canadian Journal of Chemical Engineering 63 (1985) 8-13.

[5] Z.X. Zheng, R. Yamazaki, G. Jimbo, Minimum fluidizing velocity of large particle sat elevated temperatures, Kagaku Kogaku Rombunsha 11 (1985) 115.

[6] K. Doichev, N.S. Akhmakov, Fluidization of polydisperse systems, Journal of Chemical Engineering Science 34 (1979) 1357-1359.

[7] H.J. Ryu, N.Y. Lim, D.H. Bae, Minimum fluidization velocity and transition velocity to fast fluidization of oxygen carrier particle for chemical-looping combustor, HWAHAK KONGHAK 41 (2003) 624-631. 


\section{International Journal of Science and Research (IJSR) \\ ISSN (Online): 2319-7064}

Index Copernicus Value (2013): 6.14 | Impact Factor (2014): 5.611

[8] K.F. Cen, M.J. Ni, Z.Y. Luo, Circulating Fluidized Bed Boilers Design and Operations, fifth ed. China Electric Power Press, Beijing, 1998.

[9] H.C. Liu, Z.J. Lin, C.M. Chu, Investigations on the cold state aerodynamic characteristics in a fluidized bed, Journal of Huazhong University of Science and Technology11 (1983) 103-110.

[10]Z.D. Chen, X.P. Chen, Y. Wu, Study on minimum fluidization velocity at elevated temperature, Proceedings of the CSEE 30 (2010) 21-25.

[11] S.Y. Wu, J. Baeyens, Effect of operating temperature on minimum fluidization velocity, Journal of Powder Technology 67 (1991) 217-220.

[12] J.H. Subramani, M.M. Balaiyya, R.L. Miranda, Minimum fluidization velocity at elevated temperatures for Geldart's Group-B powders, Journal of Experimental Thermal and Fluid Science 32 (2007) 166-173.

[13] S. Ergun, Chem. Eng. Prog. 48 (1952) 89.

[14] C.Y. Wen, Y.H. Yu, Chem. Eng. Prog. Symp.Ser. 62 (1966) 100.

[15] T. Mii, K. Yoshida, D. Kunii, J. Chem. Eng. Japan 6 (1973) 100.

[16] S.P. Babu, B. Shah, T. Talwalker, AIChE Sym. Ser. 74 (1978) 176.

[17] W.C. Yang, D.C. Chitester, R.M. Kornusky, D.L. Keairns, AIChE J. 31(1985) 1086.

[18] A.K. Bin, Can. J. Chem. Eng. 64 (1986) 854.

[19] M. Nakamura, Y. Hamada, S. Toyama, A.E. Fouda, C.E. Capes, Can. J.Chem. Eng. 63 (1985) 8.

[20] R.R. Pattipati, C.Y. Wen, Ind. Eng. Chem. Process Des. Dev. 20 (1981)705.

[21] A. Lucas, J. Arnaldos, J. Casal, L. Puigjaner, Ind. Eng. Chem. Process Des.Dev. 25 (1986) 426.

[22] L.E. Brownell, H.S. Dombrowski, C.A. Dickey, Chem. Eng. Prog. 46(1950) 415.

[23] R. Yamazaki, N. Ueda, G. Jimbo, J. Chem. Eng. Japan 19 (1986) 251.

[24]H.G. Kim, I.O. Lee, U.C. Chung, Y.H. Kim, ISIJ Int. 40 (2000) 16.

[25] K.C. Biswal, T. Bhowmik, G.K. Roy, Chem. Eng. J. 30 (1985) 57.

[26] S. Agrawal, G.K. Roy, Indian Chem. Eng. 30 (1988) 40.

[27] Y. Peng, L.T. Fan, Chem. Eng. Sci. 52 (14) (1997) 2277-2290.

[28] D.C. Sau, S. Mohanty, K.C. Biswal, Chem. Eng. J. 132 (1-3) (2007)151-157.

[29] M.J. Botterill, Y. Teoman, K.R. Yuregir, The effect of operating temperature on thevelocity of minimum fluidization, bed voidage and general behaviour, Journal of Powder Technolog31(1982)101-110.

[30] R.R. Pattipati, C.Y. Wen, Minimum fluidization velocity at high temperatures, Journal of Industrial \& Engineering Chemistry Process 20 (1981) 705-707

[31] J.H. Goo, M.W. Seo, S.D. Kim, Effect of temperature and particle size on minimum fluidization and transport velocities in a dual fluidized bed, in: Proceedings of the20th International Conference, Xi'an, 2009, pp. 305309

[32] S.Y. Wu, J. Baeyens, Effect of operating temperature on minimum fluidization velocity, Journal of Powder Technology 67 (1991) 217-220
[33]J.H. Subramani, M.M. Balaiyya, R.L. Miranda, Minimum fluidization velocity at elevated temperatures for Geldart's Group-B powders, Journal of Experimental Thermal and Fluid Science 32 (2007) 166-173

[34] B. Formisani, R. Girimonte, L. Mancuso, Analysis of the fluidization process of particle beds at high temperature, Journal of Chemical Engineering Science 53 (1998) 951961

[35] L.L. Chiou, M.Y. Wey, S.D. You, The effect of particle size distribution on minimum fluidization velocity at high temperature, Journal of Powder Technology 126(2002) 297-301

[36] Abrahamsen, A.R. \& Geldart, D. (1980). Behaviour of Gas-Fluidized Beds of fine powders Part I. Homogeneous expansions, Powder Technology, 26, 3546

[37] Cranfield, R.R., Geldart, D. (1974). Large particle fluidisation. Chemical Engineering Science 29 (4), 935947

[38] Davies, L. \& Richardson, J.W., (1996). Gas Interchange between bubbles and the continuous phase in a fluidized bed, Trans. Inst. Chem. Eng., 44, T293

[39] Escudero, D., and Heindel, T.J. (2011). Bed Height and Material Density Effects on Fluidized Bed Hydrodynamics, Chemical Engineering Science, 66(16), 3648-3655.

[40] Girimonte, R. \& Formisani ,B. (2009). The minimum bubbling velocity of fluidized beds operating at high temperature, Powder Technology, 189 (1), pg. 74-81.

[41] Hilal, N. (2005). The dependence of solid expansion on bed diameter, particles material, size and distributor in open fluidized beds, Advanced Powder Technology, 16(1),73-86

[42]Khani, M.H. (2011). Models for prediction of hydrodynamic characteristics of gas-solid tapered and mini-tapered fluidized beds, Powder Technology, 205, 224-230

[43]Kunii, D., \&Levenspiel, A. (2005). Fluidization engineering second edition, Newton, MA: ButterworthHeinemann

[44]Peng, Y., \& Fan, L.T. (1997), Hydrodynamic characteristics of fluidization in liquid-solid tapered beds, Chemical Engineering Science, 52 (14), 22772290.

[45] Sau, D.C., Mohanty, S., \&Biswal, K.C. (2010). Experimental studies and empirical models for the prediction of bed expansion in gas-solid tapered fluidized beds, Chemical Engineering and Processing: Process Intensification, 49(4), 418-424.

[46] Sau, D.C., Mohanty, S., \&Biswal, K.C. (2007). Minimum fluidization velocities and maximum bed pressure drops for gas-solid tapered fluidized beds, Chemical Engineering Journal, 132(1-3), 151-157

[47] Singh, R.K. \& Roy, G.K. (2005). Prediction of minimum bubbling velocity, fluidization index and range of particulate fluidization for gas-solid fluidization in cylindrical and non-cylindrical beds, Powder Technology, 159(3), 168-172

[48] Sau, D.C., Mohanty,s. \& Biswal K.C. (2008) Minimum fluidization velocity at elevated temperature in tapered fluidized bed Chemical Engineering and Processing: 47 (2008) 2391-2394

\section{Volume 5 Issue 2, February 2016}




\section{Author Profile}

Deo Karan Ram received the B.E. and M.Tech. Degree in Chemical Engineering from GGV Institute of Technology, Bilaspur and National institute of Technology, Rourkela[INDIA] in 2005 and 2009, respectively. During 2009-2011, he stayed in GGV Institute of Technology, Bilaspur [India] as faculty and he is now in National institute of Technology, Rourkela [INDIA] as Ph.D. Research Scholar.

Alok Tiwari received the B.E. and M.Tech. Degree in Chemical Engineering from GGV Institute of Technology, Bilaspur and UPES Dehradun [INDIA] in 2011 and 2014, respectively. During 2015-2016, he stays now in GGV Institute of Technology, Bilaspur [India] as faculty. 